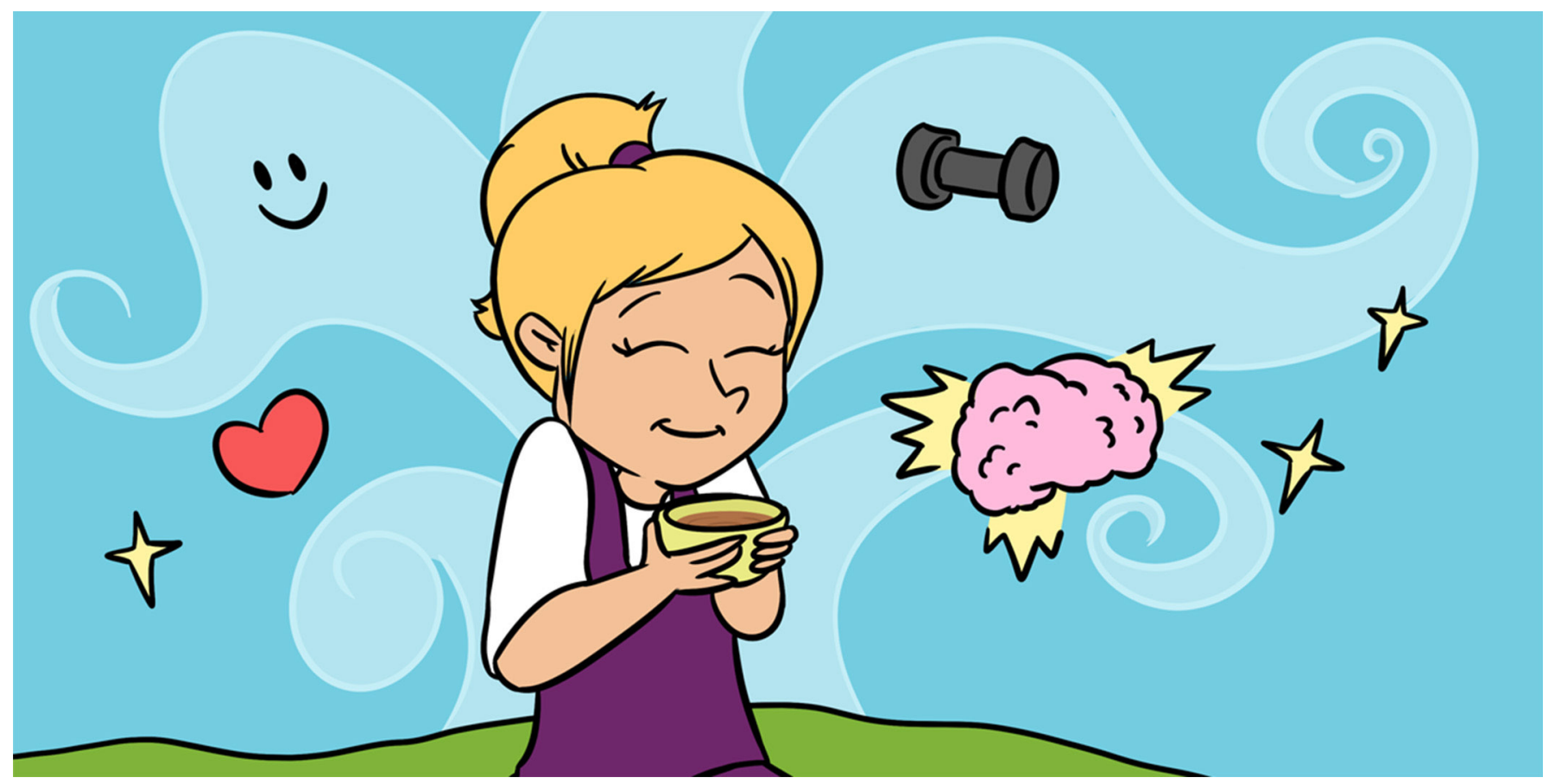

\title{
IS TEA A SUPERFOOD?
}

\section{Viduranga Y. Waisundara*}

Australian College of Business and Technology - Kandy Campus, Kandy, Sri Lanka

\section{YOUNG REVIEWER:}

CAMERON AGE: 15
The term "superfood" is constantly used nowadays to describe food products that have certain ingredients in them that are believed to prevent the occurrence of diseases. The term differs slightly from "functional foods," which are actually whole (non-processed) foods, such as nuts or legumes, that have are complex and nutrient-rich and provide well-being beyond what the body needs to simply survive [1]. Superfoods have more active ingredients than functional foods, and superfoods are associated with the ability to fight specific disease conditions, such as diabetes, cancer, and heart disease. Tea is a beverage consumed around the world that is claimed to be a superfood. This is because tea has a lot of catechins, which are compounds that are believed to prevent many diseases and disorders. These days, almost every country has tea available, and although it may not be grown in all these regions, it can be found in all supermarkets. 


\section{SUPERFOODS}

Food products that have much more active ingredients than functional foods, and have the specific ability to fight diseases due to the existence of these active ingredients.

\section{FUNCTIONAL} FOODS

Whole foods that have a complex and nutrient-rich composition and provide well-being beyond what the body simply needs to survive.

\section{WHAT IS A SUPERFOOD?}

There are lots of people around the world who have diseases that do not have an easy cure. Diabetes, cancer, and heart disease are some of these uncurable disease conditions. It is a well-understood fact that a person's everyday lifestyle plays a very important role in maintaining health and wellness, as well as in reducing the incidence of these diseases [2]. Food is a very important aspect of lifestyle, since our bodies are ultimately a product of what we eat every day.

The term "superfood" was coined to define food products that are lowcalorie, nutrient-dense, and contain active ingredients that decrease the risk of the diseases mentioned above. The active ingredients are very small molecules or chemicals that exist naturally in the foods and have the ability to stop the occurrence of diseases. Superfoods are mostly plant-based or animal-based and have many such active ingredients as well as other essential nutrients such as vitamins and minerals, which have the ability to maintain good health when consumed [3]. Some of the food products that have received recognition as superfood are blueberries, nuts, seeds, sardines, and mackerels.

Although the term "superfood" is quite popular, most scientists do not use this term and consider it to be a marketing gimmick. In fact, if a food product is labeled as a superfood, people might start to consume too much of that product and not eat a balanced diet. Thus, one must bear in mind that just because a food is called a superfood, this does not mean that consuming this product will definitely prevent the occurrence of dangerous diseases.

You might also have some confusion about the difference between the terms "functional food" and "superfood." Both terms are commonly used nowadays, and they are sometimes used to refer to the same food product, although they actually describe to two very different categories of foods. Functional foods are whole foods that have a complex and nutrient-rich composition, providing well-being beyond what the body simply needs to survive [1]. An example of a functional food is the purple or gold potatoes which have enriched contents of beneficial compounds such as anthocyanins or carotenoids. On the other hand, the term "superfood" is used to refer to food products that have much more of an active ingredient (or ingredients) than functional foods do, and superfoods (such as berries, nuts, and seeds), as I mentioned earlier, the specific ability to fight diseases because of these active ingredients. Abiding these definitions, the purple or gold potatoes are functional foods and not superfoods, because they have only one component which is specifically beneficial to health. At the same time, to make 
this clearer, superfoods specifically aim at preventing a particular disease, whereas functional foods may not have such a specific disease to prevent, but instead aim at maintaining general health and wellness.

Tea is consumed around the world and is one of the beverages that is considered a superfood. There are lots of health benefits associated with drinking tea and tea has a lot of active ingredients that have disease-fighting properties. In order to explore whether tea is actually a superfood, first, let us get to know more about tea itself, its history and origins.

\section{TEA AND ITS ORIGINS}

Tea is the second most consumed beverage around the world, after water. The scientific name of the tea plant is Camellia sinesis. Tea grows in the form of bushes (Figure 1) and is typically cultivated in tropical and sub-tropical climates. A tea plant can grow up to $16 \mathrm{~m}$ in height, but they are generally pruned to waist height for ease of plucking the top part (i.e., the bud), which is used for preparation of the tea drink.

The habit of drinking tea originated southwest China, where it was used at that time as a medicinal drink. Tea was popularized as a recreational drink during the Tang dynasty in China, and this habit eventually spread to other countries in East Asia. During the sixteenth century, Portuguese priests and merchants introduced tea to Europe. Following this, during the seventeenth century, the British adopted the habit of drinking tea and because it was considered "fashionable," large-scale production tea began at this time.

At present, around the world, more tea manufactured than coffee, soft drinks, or even alcohol. The top five countries that are the largest

Figure 1

(A) A tea bush and (B) a tea plantation, photographed next to the Castlereagh Reservoir in Sri Lanka.
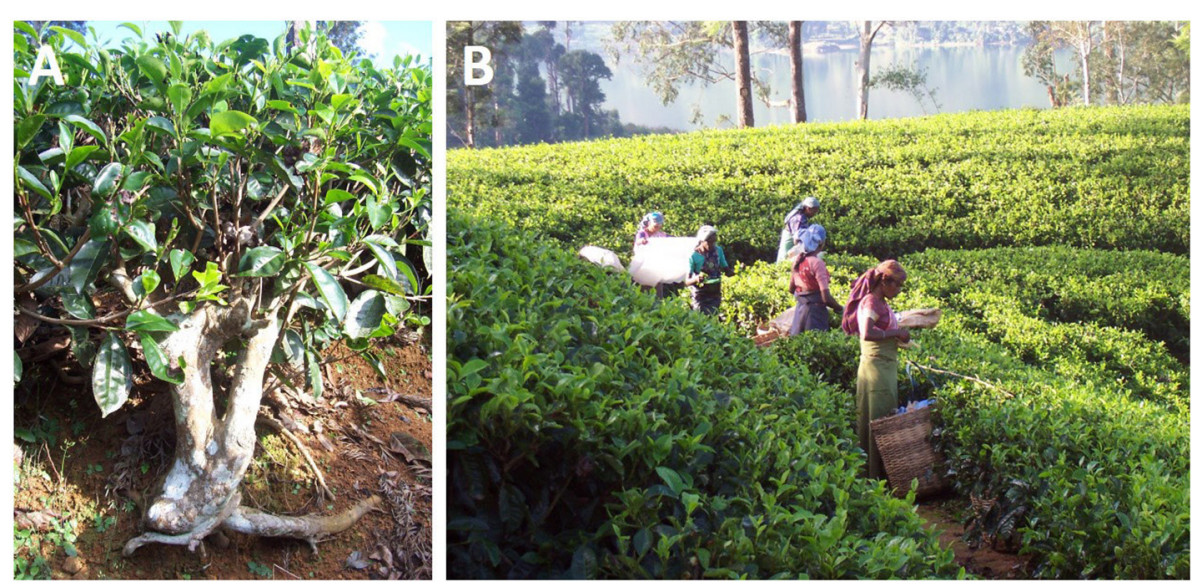

Figure 1 


\section{Table 1}

Top 5 largest producers of tea in 2016 (FAOSTAT, 2016)

\section{CATECHINS}

A group of compounds present in tea, imparting several health benefits.

\section{ANTIOXIDANT}

A group of compounds which are able to fight the chemicals which are present in our body which cause diseases.

\section{Figure 2}

Health benefits associated with the habit of drinking tea.

\begin{tabular}{|c|c|}
\hline Country & Production (millions of tons) \\
\hline China & 2.4 \\
\hline India & 1.3 \\
\hline Kenya & 0.5 \\
\hline Sri Lanka & 0.3 \\
\hline Turkey & 0.2 \\
\hline
\end{tabular}

producers of tea around the world are listed in Table 1. Most of the tea produced in these countries is bought and consumed by Russia, the UK, and the USA (in reducing order of consumption).

\section{HEALTH BENEFITS OF DRINKING TEA}

There are lots of health benefits that are associated with the habit of drinking tea. Some of these are summarized in Figure 2.

These health benefits of tea are due to a group of active ingredients known as catechins. These chemicals are not unique to tea, and can also be found in plants such as cocoa and prune juice. The bitterness in tea as well as the dryness that you feel in your mouth after drinking tea is because of the catechins. The antioxidant property of tea, which is one of the famous characteristics of this beverage, is also due to the catechins. In addition, the reddish brown color that is typically seen in

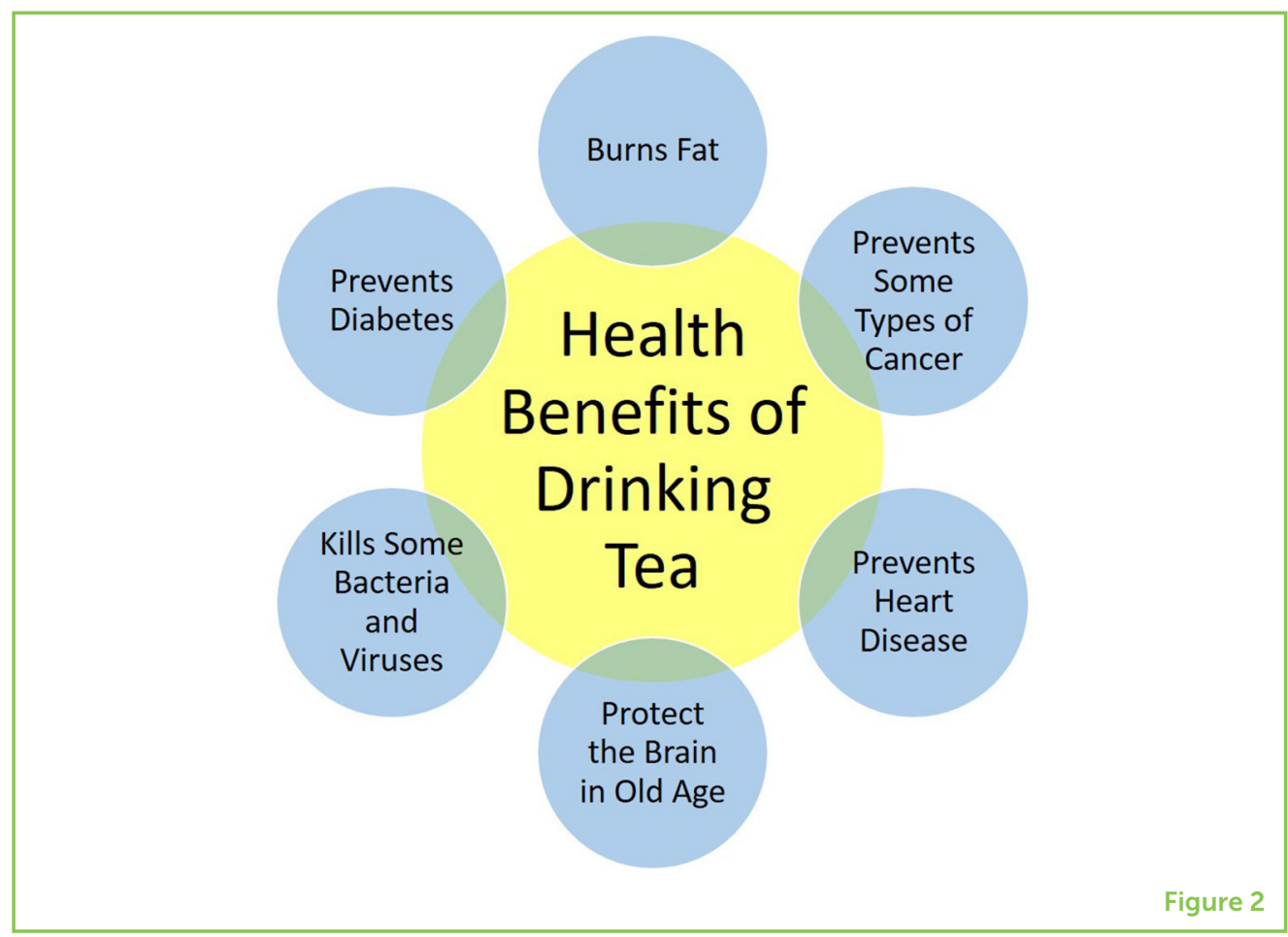




\section{TANNINS}

A group of compounds present in tea that are made from condensed catechins.

\section{FREE RADICALS}

The chemicals which are produced in our body which are believed to cause several diseases such as diabetes, cancer, and heart disease.

\section{CULTIVAR}

Plants which have advantageous characteristics and are selectively grown for agricultural purposes.

\section{Table 2}

A summary of the typical processing steps that are used to produce the various types of tea available in supermarkets around the world.

English breakfast tea is because of catechins that have been condensed together to form another group of chemicals called tannins. Tannins are also an important group of compounds when it comes to health benefits and more than anything, for providing the different tastes and aromas of various types of teas.

Catechins work to prevent the occurrence of diseases by quenching compounds called free radicals. Free radicals can cause damage to the important molecules in the body, such as lipids, proteins, and carbohydrates. In some cases, damage to these bodily molecules is the root cause behind diabetes, cancer, and cardiovascular disease-to name but a few diseases. Catechins have the ability to arrest the activity of these free radicals by neutralizing them.

\section{TEA PROCESSING}

The amount of active ingredients in brewed tea, which is typically prepared by adding hot water, depends on how the tea leaves are processed. If you go to the supermarket, you might see various types of tea available for purchase, such as green tea, black tea, English breakfast tea, or oolong tea. These come from different types, called cultivars, of tea bush. Although the flavor of the dried tea leaves themselves is determined by the type of tea bush and the quality of the plucked tea leaves, the way the tea leaves are processed, or dried, ultimately determines the aroma and taste of the final tea product. The various processing steps for some of the most common teas available in supermarkets are summarized in Table 2. Sometimes, there can be additional steps incorporated into the processes described, to make many more varieties of tea. The color of the brewed tea (after adding hot water) that is shown in this table may vary, depending on the

\begin{tabular}{|c|c|c|}
\hline Type of tea & Processing method & Color of the brewed tea product \\
\hline Green Tea & $\begin{array}{l}\text { Fresh tea leaves are steamed and } \\
\text { dried for preservation }\end{array}$ & $\begin{array}{l}\text { Light green with a slight yellowish } \\
\text { tinge }\end{array}$ \\
\hline Yellow Tea & $\begin{array}{l}\text { Fresh tea leaves are first steamed } \\
\text { and then dried }\end{array}$ & Greenish yellow \\
\hline Black Tea & $\begin{array}{l}\text { Fresh tea leaves are dried either in } \\
\text { sunlight. or inside warmed rooms }\end{array}$ & $\begin{array}{l}\text { Dark brown or reddish brown, } \\
\text { depending on the amount of tea } \\
\text { added to hot water }\end{array}$ \\
\hline Oolong Tea & $\begin{array}{l}\text { Drying of the fresh tea leaves } \\
\text { is done under strong sunlight. } \\
\text { Exposure to sunlight continues until } \\
\text { the tea leaves curl (This does not } \\
\text { happen when preparing black tea.) }\end{array}$ & Dark brown \\
\hline
\end{tabular}


cultivar, the age of the tea leaves, and the growing conditions, such as the location, soil properties, climate, and agriculture practices. For instance, black tea leaves obtained from Sri Lanka may have a higher level of tannins and may thus have a darker brown hue, whereas black tea leaves from China may have a lesser amount of tannins and therefore a lighter brown hue. The variety of tea bushes grown in various countries can also differ based on the market to which they are exported. For instance, the Sri Lankan tea industry caters to the English breakfast tea market, whereas China furnishes its tea products more to the green tea market.

The health benefits of the varieties of tea mentioned in Table 2 may vary from type to type, and the scientific evidence in support of these variations may be quite overwhelming and confusing. Overall, it is important to note that all these types of tea have catechins, and the catechins are the most important of all compounds present in tea, when it comes to tea's health benefits.

\section{TEA AS A SUPERFOOD}

Now, back to the question of whether tea is indeed a superfood. As mentioned before, although this term itself is mostly used for marketing purposes rather than as a scientific definition, it can essentially be used to describe foods that contain disease-preventing active ingredients, such as the catechins found in tea. So, in this sense, tea could indeed be considered a superfood. For one thing, tea has been associated with the prevention of many of the major diseases that are huge health problems nowadays. It is known that people who drink tea regularly have a reduced incidence of diabetes and cancer. The exact mechanisms of action by which tea decreases the occurrence of these diseases is not yet fully understood, and some scientists do not believe tea helps to prevent diseases at all, so whether tea can actually fight diseases or not is still under debate. Nevertheless, given that both cancer and diabetes may involve free radicals, it is possible that antioxidant compounds, such as the catechins in tea, do have the ability to block free radicals and help prevent these diseases.

Superfoods are typically nutrient dense, and so is tea. Along with catechins, tea also has minerals (such as manganese) and amino acids that are necessary for our metabolism. Thus, drinking tea can easily be seen as a good habit for maintaining health and wellness. Regardless of whether the term "superfood" a marketing gimmick, it seems obvious that tea is marketable as a healthy and beneficial beverage. 
Most superfoods have one drawback, and that is that they are not easily found everywhere in the world. However, tea is readily found all around the world nowadays. It can be brought from supermarkets and in many other places. There are many varieties of tea to choose from, depending on the tea drinker's preference for aroma and taste. Tea can be easily prepared in any household-it is just a matter of adding hot water and maybe a little bit of sugar to mask the bitterness (which occurs because of the tannins).

Anyone can drink tea without having any toxic side effects. Some superfoods have negative side effects when they are eaten in large quantities, but tea does not have this drawback.

However, having said all that, everything should be consumed in moderation, and thus, drinking tea should be done with a certain level of balance as well.

\section{REFERENCES}

1. Shiomi, N. (ed.). 2018. "Introductory chapter: design of an ideal diet using common foods," in Current Topics in Superfoods (Rijeka: InTech Open).

2. Shiomi, N., and Waisundara, V. Y. (eds.). 2017. Superfood and Functional Food: An Overview of Their Processing and Utilization. Rijeka: InTech Open.

3. Waisundara, V. Y., and Shiomi, N. (eds.). 2017. Superfood and Functional Food: The Development of Superfoods and Their Roles as Medicine. Rijeka: InTech Open.

SUBMITTED: 5 July 2018; ACCEPTED: 05 December 2018;

PUBLISHED ONLINE: 08 January 2019.

EDITED BY: Valeria Costantino, University of Naples Federico II, Italy

CITATION: Waisundara VY (2019) Is Tea a Superfood? Front. Young Minds 6:73. doi: 10.3389/frym.2018.00073

CONFLICT OF INTEREST STATEMENT: The author declares that the research was conducted in the absence of any commercial or financial relationships that could be construed as a potential conflict of interest.

COPYRIGHT @ 2019 Waisundara. This is an open-access article distributed under the terms of the Creative Commons Attribution License (CC BY). The use, distribution or reproduction in other forums is permitted, provided the original author(s) and the copyright owner(s) are credited and that the original publication in this journal is cited, in accordance with accepted academic practice. No use, distribution or reproduction is permitted which does not comply with these terms. 


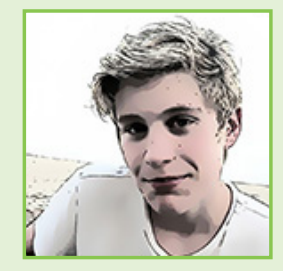

\section{YOUNG REVIEWER}

\section{CAMERON, AGE: 15}

I am in S4 at my school in Scotland. My favorite subjects are Physics and Maths. In my free time, I like Swimming, Hockey, and Debating.

\section{AUTHOR}

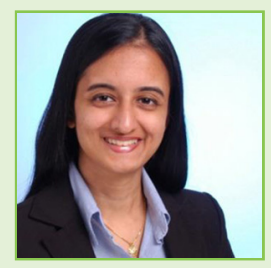

\section{VIDURANGA Y. WAISUNDARA}

I enjoy cooking. I like to create dishes that are healthy as well as delicious. I also like to drink tea, especially "tieguanyin" (铁观音), which is a premium variety of the Chinese oolong tea. My primary research interest is developing novel food products which have anti-diabetic properties. I have also conducted research on developing new beverages with health benefits. In my spare time, I like to play the piano and also likes to meditate and read books on mindfulness and healthy living. *viduranga@gmail.com 